Western University

Scholarship@Western

Department of Economics Research Reports

Economics Working Papers Archive

1984

\title{
The Regional Economic Consequences of Tariffs and Domestic Transportation Costs
}

James R. Melvin

Follow this and additional works at: https://ir.lib.uwo.ca/economicsresrpt

Part of the Economics Commons

Citation of this paper:

Melvin, James R.. "The Regional Economic Consequences of Tariffs and Domestic Transportation Costs." Department of Economics Research Reports, 8416. London, ON: Department of Economics, University of Western Ontario (1984). 
ISBN: $0-7714-0585-5$

ISSN : $\quad 0318-725 \mathrm{X}$

\section{RESEARCH REPORT 8416 \\ THE REGIONAL ECONOMIC CONSEQUENCES \\ OF TARIFFS AND DOMESTIC \\ TRANSPORTATION COST S*}

by

James R. Melvin

Department of Economics Library

OCT IO 1984

October, 1984

University of Western Ontario

\footnotetext{
* I would like to thank Lorraine Eden and Ron Jones for helpful comments on an earlier draft. I am particularly indebted to the Ontario Economic Council for funding a larger study from which this paper was derived.
} 
THE REGIONAL ECONOMIC CONSEQUENCES OF TARIFFS AND

DOMESTIC TRANSPORTATION COSTS

\section{Introduction}

When one reads the literature in regional economics one is struck by the almost complete neglect of the effect that international trade could have on regional welfare. There is also little consideration of the differential consequences that trade policy could have among regions. The traditional theory of international trade, on the other hand, in order to focus attention on trade among nations, has almost entirely abstracted from trade which may take place within a country and on the interactions between these two kinds of exchange. Indeed, the traditional models treat countries as points in space which present well-defined excess supply and demand vectors to the rest of the world. Transportation costs have never played an important role in theoretical trade models, and what little discussion there is concentrates on the costs of transporting commodities between countries. There is virtually no discussion of the role which interregional transportation costs could play in determining the country's trade patterns or the effectiveness of trade policies such as tariffs. There may, of course, be situations in which the traditional trade assumptions are quite appropriate. For small homogeneous countries which typically trade with distant partners this approach may be quite acceptable. On the other hand there clearly are countries which are made up of geographically separated regions and where the transportation costs between these regions may well be larger than the transportation costs with neighbouring countries. Canada provides an obvious example where it is often true that East-West transportation costs are higher than are transportation costs to the closer markets in the United States. And for the United States 
transportation to Canadian markets, or even to markets in Europe or Japan, could be less codtly than transporting commodities from one coast to the other, or from the north to the south. In such cases the regional consequences of transportation costs and tariffs and their interactions may be quite important.

In this paper some of the implications for regional policy of the explicit introduction of domestic transportation costs and the interaction with tariffs are considered. The traditional international trade model is extended to a regional context and some of the traditional regional problems and policy prescriptions are investigated. In Section II the model is introduced and some of the basic implications for trade are developed. Tariffs and taxes are introduced in Sections III and IV, and the implications are compared with the traditional trade results. Section $V$ examines the regional consequences of trade and tariff policy, and the principal conclusions are summarized in Section VI.

II. The Basic Model

In its basic form the model is the standard one. There are two goods, $\mathrm{X}$ and $\mathrm{Y}$, produced with capital, $\mathrm{K}$, and labour, $\mathrm{L}$, under conditions of constant returns to scale. Both factors are assumed to be in fixed supply for the economy. For simplicity, it is assumed that preferences within the domestic economy are identical among regions and can be represented by a set of commanity indifference curves. ${ }^{1}$ The assumption that tastes are the same among regions is made to focus attention on the effects of different regional endowments of factors. The assumption that tastes can be represented by a set of community indifference curves is made to simplify the analysis, and as I have shown elsewhere could easily be relaxed. (See Melvin, 1985.) It 
is also assumed throughout that the country is small and faces a fixed world terms of trade. This assumption is not crucial but allows one to focus on domestic policy issues.

Our departure from the traditional model comes by assuming that the domestic economy consists of two regions, the East, E, and the West, W. It is further assumed that transportation costs between these two regions are greater than are transportation costs between either region and the rest of the world. For simplicity, we will assume that positive domestic transportation costs exist, and that international transportation costs are zero. Such an extreme case is not required, but does simplify the analysis. Our final assumption is that the rest of the world (ROW) is so large and integrated that commodity prices everywhere are equalized. Thus the two regions in our domestic economy face the same set of world prices. Relaxing this assumption presents no particular difficulty from a qualitative point of view.

To illustrate how the domestic economy can be "regionalized" it is convenient to use an extension of a technique developed by Lancaster (1957). ${ }^{2}$ Figure 1 represents the factor box diagram for the entire economy, and with commodity $\mathrm{X}$ assumed to be labour intensive we have the production contract curve $\mathrm{O}_{\mathrm{X}} \mathrm{AO}_{\mathrm{Y}}$. With the economy assumed to face fixed relative prices, $\mathrm{P}$, equilibrium would be at a point such as $A_{\text {. If from }} O_{X}$ we draw a line with slope equal to the capital-labour ratio in industry $Y$, and from $\mathrm{O}_{\mathrm{Y}}$ a line with slope equal to the capital-labour ratio in industry $\mathrm{X}$, we construct a parallelogram $\mathrm{O}_{\mathrm{X}} \mathrm{AO}_{\mathrm{Y}} \mathrm{B}$.

The allocation of the economy's total supply of factors between the two regions can be represented by some point within the factor box. Thus point $\mathrm{N}$ could represent the endowment of region $\mathrm{E}$ measured from $\mathrm{O}_{\mathrm{X}}$ and the 
endowment of $\mathrm{W}$ measured from $\mathrm{O}_{\mathrm{Y}}$, where we have assumed that $\mathrm{E}$ is well endowed with capital relative to $W_{\text {. }}$ If point $N$ lies within the parallelogram, then since the same production functions are available in both regions, both $\mathrm{E}$ and $W$ can produce both commodities with the same relative factor prices that would have existed had all factors been available at a single location. A contract curve for region $E$ could be drawn through $O_{X} A_{E} N$, and a similar

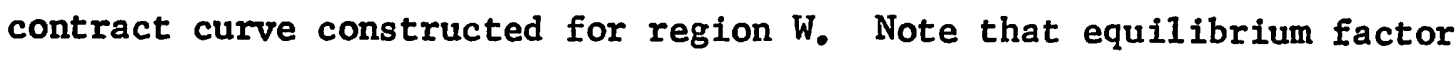
price ratios at $A_{E}, A$, and $A_{W}$ must all be the same, and equilibrium commodity prices for both regions and the economy as a whole would be identical. In Figure 2 the production possibilities curve for the entire economy is represented as TAT' with the transformation curves for the two regions similarly labelled. With price ratio $P$, production points are $A, A_{E}$, and $A_{W}$, which correspond to the similar points in Figure 1. Note that $A_{E}$ and $A_{W}$ sum to $A$, and that this will be true for the production points corresponding to any commodity price line.

There is, of course, no reason to expect endowment point $N$ to lie inside the parallelogram $\mathrm{BO}_{\mathrm{X}} \mathrm{AO}_{\mathrm{Y}}$. If it lies outside the parallelogram then either or both of the two regions must specialize in one or the other of the two commodities. Specifically, in area $I$ region $W$ will specialize in commodity $\mathrm{X}$, in area II region $\mathrm{E}$ will specialize in commodity $\mathrm{Y}$, and in area III $\mathrm{E}$ specializes in $\mathrm{Y}$ and $\mathrm{W}$ in $\mathrm{X}$. Note, also, that the question of whether both goods can be produced in equilibrium in both regions, or whether one or both regions will specialize, will depend on commodity prices. For example, with endowment point $\mathrm{N}$ specialization by region $\mathrm{E}$ or region $\mathrm{W}$ can be generated by making the relative price of $X$ higher or lower. The situations where specialization occurs in one or both regions are special cases of the more 
general model where both regions produce both goods, and throughout the analysis we will assume that the endowment point lies within the factor intensity parallelogram.

Severál interesting conclusions can be drawn from Figure 2. Suppose that preferences are such that the consumption points for regions $W$ and $E$ are $C_{W}$ and $C_{E}$, respectively. With such preferences the traditional trade model which does not take account of the possibility of regional production would have $\mathrm{C}$ as the economy-wide consumption point and the vector $\mathrm{AC}$ as the trade vector, implying imports of $\mathrm{Y}$ and exports of $\mathrm{X}$. With regional production, while the aggregate consumption point would still be the same since $C_{W}$ and $C_{E}$ must sum to $C$, the trade pattern will be quite different. Recalling the assumption that transportation costs are higher interregionally than internationally we note that the trade vectors for regions $E$ and $W$ are $A_{E} C_{E}$ and ${ }_{W} C_{W}$, respectively. In terms of the aggregate economy, this gives a trade vector $C_{W}^{\prime} C_{E}^{\prime}$, where $A C_{W}^{\prime}=A_{W} C_{W}$ and $A C_{E}^{\prime}=A_{E} C_{E^{\circ}}$. Thus, with the demand assumptions implied by this diagram, region $\mathrm{W}$ exports $\mathrm{X}$ and imports $\mathrm{Y}$, while the trade pattern for region $\mathrm{E}$ is just the reverse. The economy as a whole, therefore, is observed to be importing and exporting both comodities and we have an explanation for what has been called cross-hauling, a phenomenon which has sometimes been thought to be in conflict with the standard neoclassical trade model. 3 Thus we have:

Proposition 1: If interregional transportation costs are higher than international transportation costs, and if regional trade patterns differ, then cross-hauling of identical commodities would be expected for the economy as a whole. 
Figure 2 also illustrates the fact that changes in the terms of trade can have quite different welfare consequences for the two regions. A relative increase in the price of $\mathrm{x}$, a change which would normally be considered as an improvement in the overall economy's terms of trade, will improve the welfare of consumers in region $W$ but will make consumers in E worse off. Thus we have:

Proposition 2: If regional trade patterns differ, an improvement in the terms of trade for the economy as a whole will increase welfare in one region and reduce it in the other. ${ }^{4}$

Individuals in their role as factor owners, however, are affected identically by such a change in the terms of trade regardless of their location. From the Stolper-Samuelson Theorem the real return to labour will rise in both regions, the real return to capital will fall, and as long as both regions continue to produce both goods, real factor rewards will be identical everywhere in the economy. Note also, that while an increase in the price of $X$ will cause welfare to fall in region $E$, all consumers in the economy can still be made better off following such a change in the terms of trade. An appropriate redistribution of the gains from trade can compensate the losers and make all individuals in the economy better off. Interregional transfers in Federal states such as Canada could be justified on the basis of such changes in the terms of trade. Whether such transfers are the appropriate policy will be taken up in Section $\mathrm{V}_{\text {。 }}$

The results just derived depend crucially on the fact that in the initial equilibrium the two regions trade in opposite directions. In Figure 2 if tastes were sufficiently biased towards commodity $Y$ so that 
the consumption ray lay to the left of $A_{E}$, then both regions would export $\mathrm{x}$, there would be no cross-hauling, and the welfare changes in both regions would be in the same direction for any change in the terms of trade. Region $W$ would benefit more than $E$ from such an improvement in the terms of trade, however, so there still is a differential effect. 5

III: The Effects of Tariffs

The analysis of tariffs for the situation of Figure 2 differs in several respects from that of the traditional trade model. First, since in equilibrium both goods are being imported, a tariff can be applied to either or both commodities. It can be shown that the effects of a tariff are symmetrical between regions, so to simplify the analysis we will consider the case of a single tariff. In Figure 3 (as in Figure 2) the volume of trade for $W$ is larger than the volume of trade for $E$ so that the economy as a whole is a net importer of $\mathrm{Y}$, the import commodity in $\mathrm{W}$. It therefore seems natural to consider the imposition of a tariff on $Y$. Such a tariff will have no effect on region $E$ since that region exports $Y$. In region $W$ the effects are the traditional ones associated with the imposition of a tariff for a small country. Production will move to $A_{t}$ where price line $P_{t}$ is tangent to the production possibility curve, and the new consumption point will be $C_{t}$ where the price line $P_{t}$ is tangent to an indifference curve along the world terms of trade $\mathrm{P}$. The tariff on $\mathrm{Y}$ has resulted in a significant welfare loss to region $W$, but has not affected $E$. Thus we have:

Proposition 3: A tariff results in a welfare loss of the traditional variety only for the region which imports the commodity on which the tariff is imposed.

In Figure 3 (and for other Figures throughout the paper) is is assumed that tariffs (and taxes) are returned in lump sum fashion to consumers in 
the region from which they were collected. Although this assumption has a long history in trade theory and significantly simplifies the analysis, in the present model it is not very realistic. In Figure 3, for example, it implies that all of the federal tariff revenue collected is returned to region W. If tariffs are returned in lump sum fashion to all domestic residents then there is an additional welfare loss for consumers in $W$ and a gain for residents of $\mathrm{E}$. We therefore have:

Proposition 4: If the tariff collected on a comodity is returned in lump sum fashion to all domestic consumers, residents in the region importing that good suffer an additional loss, and residents in the region exporting that comodity enjoy a welfare gain.

Proposition 4 is of interest for it demonstrates that even for a small country with no monopoly power in trade, all consumers in a region may be made better off by a tariff. This result will, of course, be more important if residents of region $E$, either because of size or political power, have more influence with the central government than do residents of $\mathrm{W}$, for they then may be able to influence the distribution of tariff revenues. While region $W$ has been disadvantaged by the tariff, we know that all residents of $\mathrm{W}$ have not shared equally in the 1oss. From the Stolper-Samuelson Theorem the return to capital will have increased and the return to labour will have decreased, both relatively and absolutely. This means that the major burden of the two types of losses identified in Propositions 3 and 4 will be borne by labour in region $W_{\text {. }}$

From international trade theory we know that a tariff, because it produces relative price differences among countries, results in a loss in world output. The same phenomenon occurs for the two regions. Because 
commodity prices in the two regions differ, a tariff will move the output of the economy to some point inside the production possibility curve TAT' of Figure 2. Similarly a tariff on commodity $\mathrm{Y}$ in Figure 3 will produce the standard tariff distortion in region $\mathrm{E}$, and will also result in the economy producing inside TAT'. Tariffs on both commodities produce both production inefficiencies, and we have:

Proposition 5: A tariff on either or both commodities produces a dead-weight production loss for the economy.

If, in Figure 3, we continue to impose higher and higher tariffs on commodity $\mathrm{Y}$ it is possible that at some point the tariff rate will become

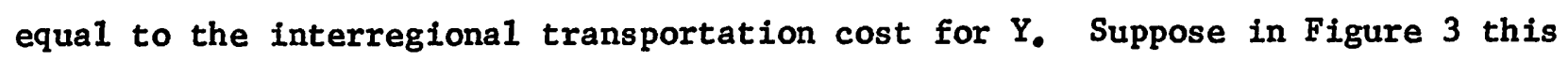
has occurred at price line $P_{t^{*}}$, With any small additional tariff region $W$ will find it cheaper to purchase commodity $\mathrm{Y}$ from region $\mathrm{E}$ rather than from ROW. Region $\mathrm{E}$ will be indifferent as to whether trade is with region $W$ or with ROW as long as region $W$ pays the entire cost of transportation. Assume that the exports of region $E$ are sufficient to satisfy the demands for imports of commodity $\mathrm{Y}$ by region $\mathrm{W}$. Region $\mathrm{W}$ now imports $\mathrm{Y}$ from $\mathrm{E}$ at the price ratio $\mathrm{P}_{t}$, and because there is now no tariff revenue, the consumption point in region $W$ will be $C_{d}$. Thus associated with the switch from international to interregional trade we have a discrete fall in consumption from $C_{t}$ to $C_{d}$. This gives:

Proposition 6: If the tariff generates interregional trade there is a discrete and instantaneous fall in domestic consumption equal to the loss in tariff revenue. 
Proposition 6 is interesting for it illustrates an unusual phenomenon。 With all functions smooth, continuous and differentiable a sma11 change in a continuous exogenous variable (the tariff rate) results in a sudden fall in an endogenous variable (utility or consumption). The cause of this discontinuity is easily seen. With imports from ROW, domestic consumers receive the tariff revenue in lump sum fashion and their maximization behaviour is unaffected by the transfer. With the tariff $(t)$ equal to the interregional transportation rate $(\tau)$, consumers in $W$ are indifferent between imports from $E$ and imports from ROW. Imports from $E$, however, require the use of real resources to produce transportation in an amount equal in value to the tariff revenue. With $t>\tau$ resources formerly used to produce consumption goods are now used to produce transportation which does not increase utility. Pursuing a tariff policy which results in such inefficient (and unnecessary) transportation is thus equivalent, from a welfare point of view, to throwing the tariff revenue in the ocean. In countries such as Canada it seems clear that the tariff structure has been designed principally to encourage domestic trade at the expense of international trade. It seems equally clear that the high costs associated with this policy have not been recognized.

Note that the entire cost of transporting $\mathrm{Y}$ from $\mathrm{E}$ to $\mathrm{W}$ must be borne by $W$. Since both regions are small with respect to ROW, $E$ can always sell $\mathrm{Y}$ at world prices, so would never share in the transport costs. The incidence of the loss of tariff revenue, however, will depend on the initial tariff revenue distribution. If tariff revenues were initially distributed equally to all domestic residents, then all consumers in the economy will suffer a welfare loss when interregional trade is generated. 
When a tariff is imposed on both commodities the results for region $E$ are analogous to those just described for region W. Both regions will initially lose since consumption will move to points such as $C_{t} \cdot$ When the tariff is high enough to overcome the transportation costs both regions will switch from trading with ROW to trading with each other, and thus both will lose at least part of the gains associated with trading internationally. Of course, there is no reason to expect that trade between the regions will just satisfy all domestic excess demands and one would expect that at least one region will be left trading with ROW.

There are several other interesting implications of the trade patterns shown in Figure 3. In the initial free trade situation $C_{W} A_{W}>A_{E} C_{E}$ implying that the economy as a whole is a net exporter of commodity $X$. With the tariff and before interregional trade $C_{t} A_{t}<A_{E} C_{W}$, so that now the economy is a net exporter of $\mathrm{Y}$.

In the case where interregional trade has been generated an even more surprising trade pattern can emerge. Suppose it were the case that the imports of $Y$ in region $W$ were just equal to the exports of $Y$ from $E$. We then have that $\mathrm{E}$ exports $\mathrm{Y}$ to $\mathrm{W}$ and imports $\mathrm{X}$ from ROW, while $\mathrm{W}$ imports $\mathrm{Y}$ from $\mathrm{E}$ and exports $X$ to ROW. Thus the economy as a whole both imports and exports $X$ and does not trade in $Y$.

Had we initially imposed a tariff on $\mathrm{X}$ we could have constructed a situation where $Y$ was both imported and exported and where $X$ was not traded internationally. Of course, neither of these special cases is to be expected, for they depend on the excess demand of one region being, by chance, just equal to the excess supply of the other. ${ }^{6}$ In general, trade in the other good would be expected. In the situation of Figure 4 one would expect some 
Y to be either imported or exported. In general, however, there will be no a priori way of predicting the trade pattern.

In the traditional international trade model the Heckscher-Oh1in Theorem provides information on trade flows from a knowledge of factor endowments, and this is true whether or not there are tariffs. Thus if TAT of Figure 1 were the traditional trade diagram we would conclude that the economy is relatively well endowed with labour and will export $\mathrm{X}$, the commodity which uses labour most intensively. In this model tariffs can reduce the volume of trade but cannot change the trade pattern. In a regional context these simple relationships can no longer be assumed. Thus:

Proposition 7: In a regional economy tariffs can reverse the pattern of net trade, and thus the Heckscher-Ohlin Theorem cannot provide a prediction of trade flows in the presence of tariffs. With interregional trade,as a special case one can have exports and imports of one commodity and no trade in the other.

Those economists still interested in explanations of the Leontief Paradox can thus add tariffs in a regional economy to their 1 ist.

In the analysis transport costs have been modeled simply as a price distortion, and it might seem more appropriate to specify a third industry which produced a transportation output (T) using capital and labour as inputs. It can be shown, however, that for a small open economy these two approaches are equivalent as long as the capital-1abour ratio for transportation lies between the capital-1abour ratios for the other two industries.

Suppose that $k_{y} \geq k_{T} \geq k_{x}$, where $k_{i}$ is the capital-labour ratio for the $i$ th industry. Further suppose that a certain quantity of transportation, 
$T_{0}$, is required to move commodity $Y$ from $E$ to $W$. The factors required to produce $T_{0}$ will be some bundle $\left(K_{0}, L_{0}\right)$. The relative commodity price ratio in $W$ will be $P_{T}<P$ reflecting the per unit transportation cost of the imported $Y$. Consider an alternative model where instead of transportation costs we have a government which wishes to raise the price of $Y$ to $P_{t}=P_{\tau}$ by taxing all imports of $Y$ from region $E$. Since $k_{y} \geq k_{t} \geq k_{x}$, consumers in $W$ could use the factor bundle $\left(\mathrm{K}_{0}, \mathrm{I}_{0}\right)$ to produce a commodity bundle $\left(\mathrm{X}_{0}, \mathrm{Y}_{0}\right)$, which, because of constant returns to scale and the conditions for profit maximization will be equal in value to $T_{0}$ and will therefore be equal to the required tax. The government is indifferent to whether the tax is paid in units of $Y$, $\mathrm{X}$, or both, since any alternative bundle can be costlessly obtained through international trade. Note that as long as the government does not redistribute the tax revenue, consumer prices and the quantities of $X$ and $Y$ available for consumption in $\mathrm{W}$ will be identical here as in the case where transportation was produced. Thus we have:

Proposition 8: If $k_{y} \geq k_{T} \geq k_{x}$, then for a small open econgmy treating interregional transportation costs as a tax on interregional imports which is not redistributed is equivalent to modeling transportation as a third produced commodity.

If $k_{T}$ is not between $k_{x}$ and $k_{y}$ the analysis is slightly more complex but essentially the same. Produced transportation cannot be seen as equivalent to a bundle of $X$ and $Y$, so that the production point must shift when $T$ is produced. However, since commodity and factor prices are determined by world prices so that factor incomes remain the same, as long as the value of resources used to produce transportation remains constant, consumption and 
utility must also be the same. The only difference from the case where $k_{y} \geq k_{T} \geq k_{x}$ is that the trade vector will be longer or shorter depending on whether $k_{\mathrm{T}}<k_{\mathrm{x}}$ or $k_{\mathrm{T}}>\mathrm{k}_{\mathrm{y}^{*}}$

Figure 3 illustrates a case where a tariff, by generating interregional trade, results in a welfare loss equal to the loss in tariff revenue. With tariff revenue distributed to all domestic residents, consumers in both $E$ and $W$ will be worse off. An assumption crucial for this conclusion is that the exports of $\mathrm{Y}$ by region $\mathrm{E}$ are sufficient to satisfy the import demands of region $W$. If this is not the case then $E$ may actually gain from the tariff. To illustrate assume that region $E$ is initially self-sufficient so that only region $W$ trades internationally. This case is shown in Figure 4 where $C_{W}$ and $C_{E}$ are the free-trade consumption points for regions $W$ and $E$, respectively. Now suppose a tariff is imposed on commodity $\mathrm{Y}$ which is higher than the interregional transportation cost. Region W will now want to import $\mathrm{Y}$ from region $\mathrm{E}$ but this can only be done by bidding up the price of $Y$ in $E$, since otherwise no $Y$ is available for export. Suppose at price $P_{E}$ region $E$ is just able to provide the quantity of $\mathrm{Y}$ demanded by region $\mathrm{W}_{\text {. N }}$ Note that the difference between the slopes of $P_{t}$ and $P_{E}$ represent the transportation costs between the two regions. Equilibrium consumption points for regions $W$ and $E$ would be $C_{a}$ and $C_{b}$, respectively.

The consequences of a tariff in region $W$ are similar to those described for Figure 3. Initially the tariff moves the consumption point from $C_{W}$ to $C_{t}$ and then the internalization of trade moves consumption from $C_{t}$ to $C_{a}$. For region $E$, however, the situation is quite different. The tariff-generated demand for region $E^{\prime}$ 's output has resulted in an improvement in the regional 
terms of trade with consumption moving from $C_{E}$ to $C_{b}$. This result is also possible for the situation of Figure 3 where $E$ initially imports $X$, and will occur if $W^{\prime}$ 's interregional demands for $Y$ are larger than $E^{\prime} s$ exports of Y. Of course, this terms-of-trade gain must be set against the welfare cost associated with the loss in tariff revenue for that region, but a net gain for $E$ is certainly possible.

This possibility of a terms-of-trade gain for $E$ can also be derived even if both regions are initially importers of $Y_{0}$ In this case a small tariff would initially eliminate trade for region $E$ and increases in the tariff would eventually result in trade in the "wrong direction". Here the tariff has resulted in a reversal in the trade patterns for region $\mathrm{E}$. Thus even for a small open economy a tariff could benefit a region, even if that tariff was initially imposed on that region's import commodity. This somewhat paradoxical conclusion results from the fact that the tariff first eliminates that region's trade with ROW, but then creates trade with the other region behind the tariff barrier. We thus have:

Proposition 9: A tariff, by generating interregional trade may improve the terms of trade for a region and increase welfare. The pattern of trade for the region can also be reversed.

Even though region $\mathrm{E}$ of Figure 4 may gain from a tariff, the economy as a whole will suffer both the traditional welfare loss and the tariff revenue loss identified in Proposition 6. Region $W$ therefore bears more than the full welfare cost of the tariff. 
IV. Taxes and Trade:

One of the standard propositions of trade theory is that a tariff structure can be duplicated by a system of domestic taxes and/or subsidies. In the context of the regional model described here where the economy imports and exports both commodities it is easily shown that this equivalence no longer holds. To illustrate consider the situation where the same tariff is applied to both goods. Such a tariff structure increases the output and reduces the consumption of $\mathrm{X}$ in region $\mathrm{E}$ and increases the consumption and reduces the output of $\mathrm{Y}$ in region $\mathrm{W}$. There is certainly no uniform tax-subsidy policy for the economy as a whole which would produce this result. Of course, if taxes are allowed to differ among regions then the tariff effects could be duplicated. This possibility will be considered in Section $\mathrm{V}$.

In Figure 5 the effects of a production tax on $Y$ and a consumption tax on $\mathrm{X}$ which apply to both regions is illustrated. This tax system is equivalent, for region $E$, to a tariff on $X$. For region $W$, the taxes are equivalent to an export subsidy moving production to $\mathrm{A}_{s}$ and consumption to $\mathrm{C}_{s}$. While for region $E$ the tax structure has the same welfare effects as a tariff, for region $W$ a tariff would have reduced welfare less. The worst that a tariff can do is eliminate trade and move the region to the autarky position. In Figure 5 the tax structure has resulted in consumption inside the production possibility curve, and thus autarky would be preferred. ${ }^{7}$ We have:

Proposition 10: If trade patterns differ between regions, a tariff system cannot be duplicated by a set of domestic taxes or subsidies. Furthermore taxes may reduce regional welfare below the autarky level.

Figure 5 implicitly assumes that the tax revenue is returned in lump sum fashion to the region from which it was collected. Any redistribution of the tax revenue will further affect the welfare of the two regions. 
The tax implications for the volume of trade are also quite different than for tariffs. A tariff will always reduce the volume of trade for the economy as a whole. 8 The tax structure of Figure 5 applied uniformly to both regions will reduce trade for one region and increase it for the other, and there can be no presumption as to how the overall volume of trade will change. Furthermore, note that in the tax equilibrium of Figure 5 the economy has become a net exporter of commodity $X,\left(C_{s} A_{s}>A_{t} C_{t}\right)$, and thus the tax structure has reversed the trade pattern. Thus:

Proposition 11: For a regional economy domestic taxes can reverse the pattern of trade. Thus the Hecksher-Ohlin Theorem cannot provide a prediction of trade flows in the presence of domestic taxes.

This is an interesting proposition, for it shows that even with free trade the Heckscher-Ohlin Theorem is not useful for predicting trade patterns. One also has yet another possible explanation of the so-called Leontief paradox.

\section{Regional Economic Policy}

As well as the implications for the traditional trade results discussed above, the explicit recognition of the regional characteristics of an open economy suggest some interesting domestic policy conclusions. Countries which are characterized by distinct regional differences often have a federal form of government, where lower levels of government (state or provincial) can be seen as representing, at least to some extent, these regions. Obvious examples are Australia, Canada and the United States. The existence of distinct regions and a federal system of government provide at least two additional policy dimensions than exist in a unitary state. First, the federal government may attempt to equalize the effects of external changes (or its own policy) across 
regions. Second, regional governments have some power to introduce their own policies, and these may either reinforce or act in opposition to federal policy. Several examples of such policies and implications for an open economy can be provided.

In Section II it was shown that improvements in the economy's terms of trade would increase welfare in $\mathrm{W}$ and reduce welfare in $\mathrm{E}$. Interregional transfers for the purpose of equalizing regional welfare or income levels could be suggested on the basis of such changes in the terms of trade. But note that since real factor rewards remain the same in the two regions (because commodity prices are the same) such transfers would result in higher real incomes to both capital and labour in E. This, of course, assumes that all residents of region $E$ share in the transfer. We have the somewhat paradoxical result that the combination of a terms-of-trade change in favour of $W$ and a transfer of income from $W$ to $E$ could leave the overall utility of region $E$ lower but the real income of all residents of $\mathrm{E}$ higher than the income of residents of $\mathrm{W}$. And note that this does not depend on the size of the transfer. Any transfer, no matter how small, will produce this result. Thus we have:

Proposition 12: Any small transfer from a gaining to a losing region to compensate for a terms-of-trade change will leave all factor owners in the losing region with higher incomes than their counterparts in the gaining region.

This seeming paradox can be resolved by noting that the regional welfare difference is just a consequence of the fact that $W$ has relatively more labourers whose incomes have risen relative to the incomes of capital owners. 
Individuals as factor owners are affected everywhere the same by a terms-oftrade change, and regional welfare differences are a consequence of different proportions of factors in the regions. This raises the issue of whether economic policy should be concerned with regions or with individuals. The observed reduction in the welfare or income of $E$ which gave rise to the transfer is a consequence of the relative income reduction suffered by capital in both regions. If this is seen as inappropriate it would seem more equitable to subsidize all domestic capital rather than all consumers in $W_{0}$ Note that the big losers of such a terms-of-trade change combined with a transfer to $\mathrm{E}$

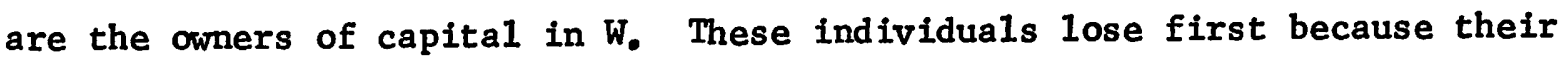
real incomes fall and second because they will presumably pay, through taxation, for the transfer to $\mathrm{E}$.

We have also seen that tariffs, through their effects on real factor rewards, can affect factor incomes across regions. In Figure 3, for example, a tariff in one or both regions will, from the Stolper-Samuelson Theorem, result in differences in real factor rewards between regions. The increase in the relative price of $\mathrm{Y}$ in region $\mathrm{W}$ will reduce the real rewards to labour and increase the real rewards to capital. If a tariff is also applied to $Y$, real returns to factors in region $\mathrm{E}$ will change in the opposite direction, so whatever the tariff structure, after a tariff has been imposed we will observe that

$$
\left(w / P_{x}\right)_{E}>\left(w / P_{x}\right)_{W} \text { and }\left(w / P_{y}\right)_{E}>\left(w / P_{y}\right)_{W}
$$

and

$$
\left(r / P_{x}\right)_{E}<\left(r / P_{x}\right)_{W} \text { and }\left(r / P_{y}\right)_{E}<\left(r / P_{y}\right)_{W}
$$

where $w$ and $r$ are the returns to labour and capital respectively. We . therefore have: 
Proposition 13: If regions have different trade patterns any tariff will generate interregional differences in real factor rewards. The abundant factor in each region will lose relatively and absolutely.

While one would not suggest that tariffs are the only reason why one might observe differences in regional factor rewards they may well be a contributing factor.

Now suppose factor mobility between regions is allowed and for simplicity assume that only labour migrates. With real wages higher in $E$ labour will leave region $W$ and move to region $E$, and a question of interest is whether this factor mobility would be expected to remove the regional factor price differences. The answer is clearly no. As long as commodity prices remain fixed in the two regions, factor mobility will have no effect on relative factor rewards. From the Rybczynski theorem we know that the movement of labour from $W$ to $E$ will increase the output of $X$ in $E$ and reduce it in $W$, and will reduce the output of $\mathrm{Y}$ in $\mathrm{E}$ and increase it in $\mathrm{W}_{\text {. Factor movements }}$ will bring the capital-labour ratios closer together in the two regions, but will not change the capital-1abour ratios for the industries, and will not change relative factor prices. Thus with unchanged commodity prices real factor rewards are unchanged, and we have:

Proposition 14: With fixed commodity prices, regional factor movements will not result in any tendency towards the equalization of factor rewards among regions.

In the regional economics literature one finds puzzlement as to why the significant amount of factor mobility which has occurred among regions has not reduced regional income differences. In his widely referenced paper Borts, referring to the United States for the periods 1919-1929 and 1948-1952, 
states that "The failure of wages to converge is rather surprising in view of the available evidence that these periods witnessed considerable interstate migration from low- to high-wage states." (1960, p. 163.) In the Canadian context the Economic Council of Canada concludes a section on Canadian regional disparities with the observation that "In sum, regional disparities in income and job opportunities are indeed substantial and remarkably persistent in spite of the amount of labour migration that has taken place over the years." (1977, p. 60.) We now see that such factor mobility should not be expected to reduce these differentials, and indeed mobility cannot affect factor prices as long as relative commodity prices are unchanged. Other more direct policies such as interregional transfers or equalization payments should also not be expected to change real factor rewards unless they also change relative commodity prices. They will, of course, change factor incomes as was noted earlier.

It has been shown that factor movements will not change factor returns as long as commodity prices remain fixed. Sufficient factor mobility, however, could result in changes in the commodity prices in either or both regions. Figure 6 shows the situation for region $E$ with $A_{E}$ and $C_{E}$ the pre-factormovement equilibrium of Figure $3 .^{9}$ An inflow of labour from region $W$ will cause $E$ to move along the Rybczynski line $A_{E} A_{R}$ and at $A_{R}$ all trade for region $E$ will have been eliminated. Factor prices will still be unequal across regions, however, and thus the labour inflow will continue. Now, since trade had been eliminated, this increase in labour will result in a gradual increase in the relative price of $Y$ as prices adjust to equate regional demands and supplies. The final equilibrium could be a point such as $C_{F^{\prime}}$. Figure 6 assumes that the tariff and the transportation costs continue to eliminate the possibility of 
trade either with region $W$ or with ROW, but this need not be the case. The opposite changes are occurring in region $W$ where the labour outflow is causing the production possibility curve to shift inward as the economy moves along its Rybczynski 1ine. Again, after trade has been eliminated, the price of $X$ will begin to fall and factor flows will cease only after commodity prices have been equalized between the two regions. At this point, of course, both regions have exactly the same capital-1abour ratios and they thus differ only in terms of size. Both will now be scaled-down versions of the overall. economy. In the final equilibrium, all the interregional distortionary effects of both the tariff and the transportation costs have been removed by factor flows, so that eventually factor mobility will eliminate differences in regional real incomes. 10 Thus:

Proposition 15: With tariffs and differing regional trade patterns, factor mobility will equalize regional factor rewards only if relative endowments are equalized among regions.

The complete equalization of regional factor prices suggested in Proposition 15 has not been observed in practice. Furthermore, given the explicit spatial nature of our model, the assumption that factors are perfectly mobile is clearly inappropriate. Just as there are transportation costs for comodities, so will there be costs of moving factors. Although the costs associated with factor relocation are typically of the once-and-for-all variety, they can be quite significant, and for labour one would not expect mobility to proceed beyond the point where the discounted value of the stream of extra earnings expected in the high-wage region were equal to the costs of relocation. For capital, relocation costs in the long run may well be small but in the 
short run could be high. Even in the long run capital may be relatively immobile if it is industry specific and/or if industries are closely associated with resources which are differentially endowed among regions. There are, then, a number of reasons why interregional factor movements would not be expected to proceed to the point where capital-1abour ratios are equal across regions. If such equalization does not take place regional differences in factor rewards will persist.

We now turn to consideration of the case where the policies of the two levels of government are in conflict. Such a possibility does not arise in the traditional international trade model where a unitary government is implicitly assumed. Returning to Figure 4 suppose the federal government has imposed a tariff on commodity $Y$, resulting in a reduction in welfare for region $W$ and an increase in welfare for $E$. The welfare loss for $W$ comes from three sources; the traditional loss associated with a tariff for a small country, the loss of tariff revenue, and the additional loss associated with the internalization of trade. To offset the last, one could pursue a policy of increasing interregional transportation costs. Such measures could increase welfare for the region (or for the entire economy) by eliminating the tariff revenue loss identified in Proposition 6. Thus we have:

Proposition 16: In the presence of tariff-induced interregional trade, increasing interregional transportation costs may be an optimal strategy for a region or for the economy as a whole.

While direct interference with interstate or inter-provincial trade is usually excluded by law, indirect measures are available. High licencing fees for trucks or other transportation modes can be imposed. Transportation 
costs can be increased by charging high taxes for gasoline or by imposing (or allowing) high terminal costs at transhipment points. And given the importance of truck transport, the provision and maintanance of highways can have an important influence on the real costs of transportation.

A simple and effective policy to counteract the tariff itself would be an appropriate commodity tax or subsidy system, assuming that the regional government has authority to levy such taxes. In Figure 4, a production tax on $Y$ and a consumption tax on $X$ both equal to the original tariff on $Y$, would move production and consumption back to $A_{W}$ and $C_{W}$ respectively. Note that such a policy would also eliminate the loss associated with tariff-induced interregional trade; the movement from $C_{t}$ to $C_{a}$. Furthermore, since interregional trade has been eliminated, the possibility of region $\mathrm{E}$ gaining from the tariff policy has also been eliminated. Thus we have:

Proposition 17: When faced with a federal tariff on a regional import a first best policy will be an offsetting system of regional taxes and/or subsidies.

Finally, note that while taxes here have been proposed as an offset to federal tariff policy, taxes could also be used to duplicate the effects of a tariff. It was shown in Section IV that taxes levied at the federal level would have quite different effects than tariffs since such taxes would apply to all regions. If taxes can be applied at the regional level, however, they can duplicate the tariffs imposed by the federal government.

\section{Summary and Conclusions}

The traditional international trade assumption that countries are points with no spatial characteristics has been a useful simplification and has resulted in a rich body of trade theory. There are circumstances, however, where the implicit assumption that all production within a country takes place 
in a single location obscures some interesting regional policy questions. For example, there has been almost no discussion of the interaction between trade policy and regional policy in the presence of transportation costs. The purpose of this paper has been to analyze some of these interactions. Beginning with a model of an economy consisting of two regions having different factor endowments and with significant transportation costs between them it was first shown that one might expect the economy as a whole to be both importing and exporting the two commodities; the phenomenon of crosshauling. It was also shown that changes in the terms of trade could have different welfare effects on the two regions.

The introduction of tariffs and taxes also produced results which differed from those of the traditional model. A tariff was shown to result in production inefficiency, and could produce inefficient interregional transportation which would also reduce welfare. In the latter case the economy may switch from collecting tariff revenue to using up resources to produce unnecessary transportation. Indeed Canadian tariff policy seems to have been designed to do precisely this. Tariffs could also result in welfare gains to a region if they result in a reversal of the trade pattern and a switch in trading partners from ROW to the other region. Thus even in a small open economy a region may be better off with a tariff. Taxes were shown to have different consequences for welfare and the volume of trade than in the traditional model, and at the federal level the traditional equivalence between tariffs and a tax system cannot be established.

It was shown that interregional transfers to correct income or welfare differences could result in lower real incomes for all factor owners of the gaining region, raising the question of whether regional incomes or factor 
incomes should be the appropriate policy target. It was also shown that tariffs could generate differences in factor rewards, and that factor mobility would not equalize these rewards unless there is enough mobility to equalize relative factor endowments across regions. Several reasons why this was not to be expected were suggested. Thus in an economy with distinct regions subjected to a tariff system, differences in regional factor rewards should be expected to persist, and attempts by governments to equalize regional incomes will almost certainly be unsuccessful. 


\section{FOOTNOTES}

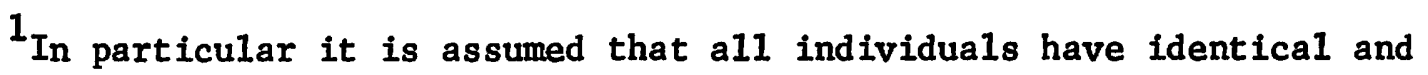
homothetic preferences. For a careful discussion of the conditions under which community indifference curves exist see Chipman (1965).

${ }^{2}$ Our dichotomization of the economy into regions is similar to that of - Bhagwati and Brecher (1980) and Brecher and Bhagwati (1981). Their concern was with domestic and foreign ownership of the factors of production.

${ }^{3}$ For an example where domestic taste differences could give rise to cross-hauling see Melvin (1983).

${ }^{4}$ Similar differential effects for terms-of-trade changes for nationals and foreigners were discussed by Brecher and Bhagwati (1981).

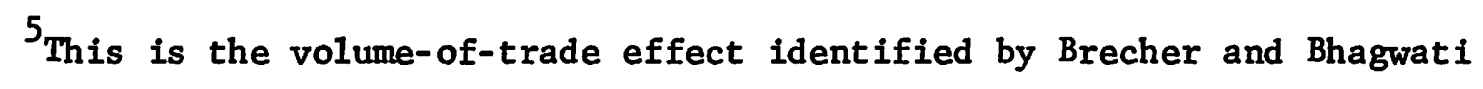
(1981).

${ }^{6}$ Demand in region $W$ should be interpreted as including the demand for transportation. Figure 4 has been drawn so that the international exports of the two regions are equal. The interregional exports of $\mathrm{Y}$ by $\mathrm{E}$ must equal the imports of $\mathrm{Y}$ by $\mathrm{W}$ plus the transportation costs. The treatment of transportation is considered further later in this section. Note also that a neutral money is required to facilitate these transactions.

${ }^{7}$ While a tax (or an export subsidy) is potentially worse than any tariff it is not always worse. It is certainly possible to construct cases where a tariff reduces welfare more than would an equal rate export subsidy.

8 Note that this will be true whether there is a tariff on only one or both commodities. 
${ }^{9}$ For simplicity it has been assumed that there is a tariff only on commodity $\mathrm{Y}_{\text {. }}$

10 Note that the production distortion of Proposition 5 has been eliminated, so that the value of domestic output is higher than in the tariff situation. 
REFERENCES

Bhagwati, J. N. and R. A. Brecher (1981), "National Welfare in an Open Economy in the Presence of Foreign-Owned Factors of Production," Journal of International Economics 10, 103-115.

Borts, H. (1960), "The Equalization of Returns and Regional Economic Growth," The American Economic Review 50, 319-347. Reprinted in D. McKee, et a1., Regional Economics: Theory and Practice (New York: Free Press), page references to the 1atter.

Brecher, A。 and J. N. Bhagwati (1981), "Foreign Ownership and the Theory of Trade and Welfare," Journal of Political Economy 89, 497-511.

Chipman, S。 (1965), "A Survey of the Theory of International Trade: Part 2, The Neo-Classical Theory," Econometrica 33, 685-760.

Economic Council of Canada (1977), Living Together: A Study of Regional Disparities (Ottawa: Government of Canada). Lancaster, K. (1957), "The Heckscher-Ohlin Trade Model: A Geometric Treatment," Economica, 19-39. Melvin, J. Ro (1985), "Domestic Taste Differences, Transportation Costs and International Trade," Journal of International Economics (forthcoming). 


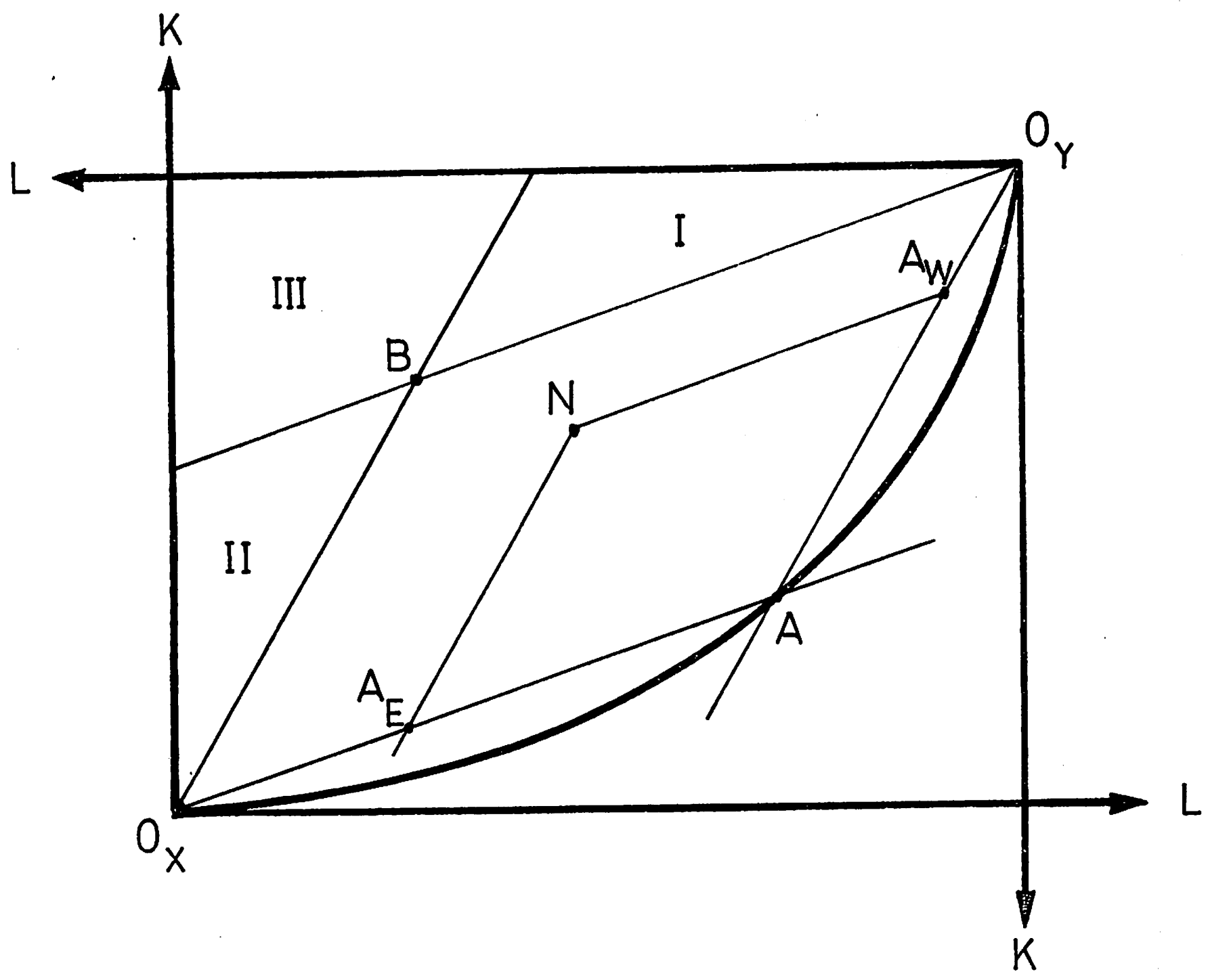

FIGURE 1 


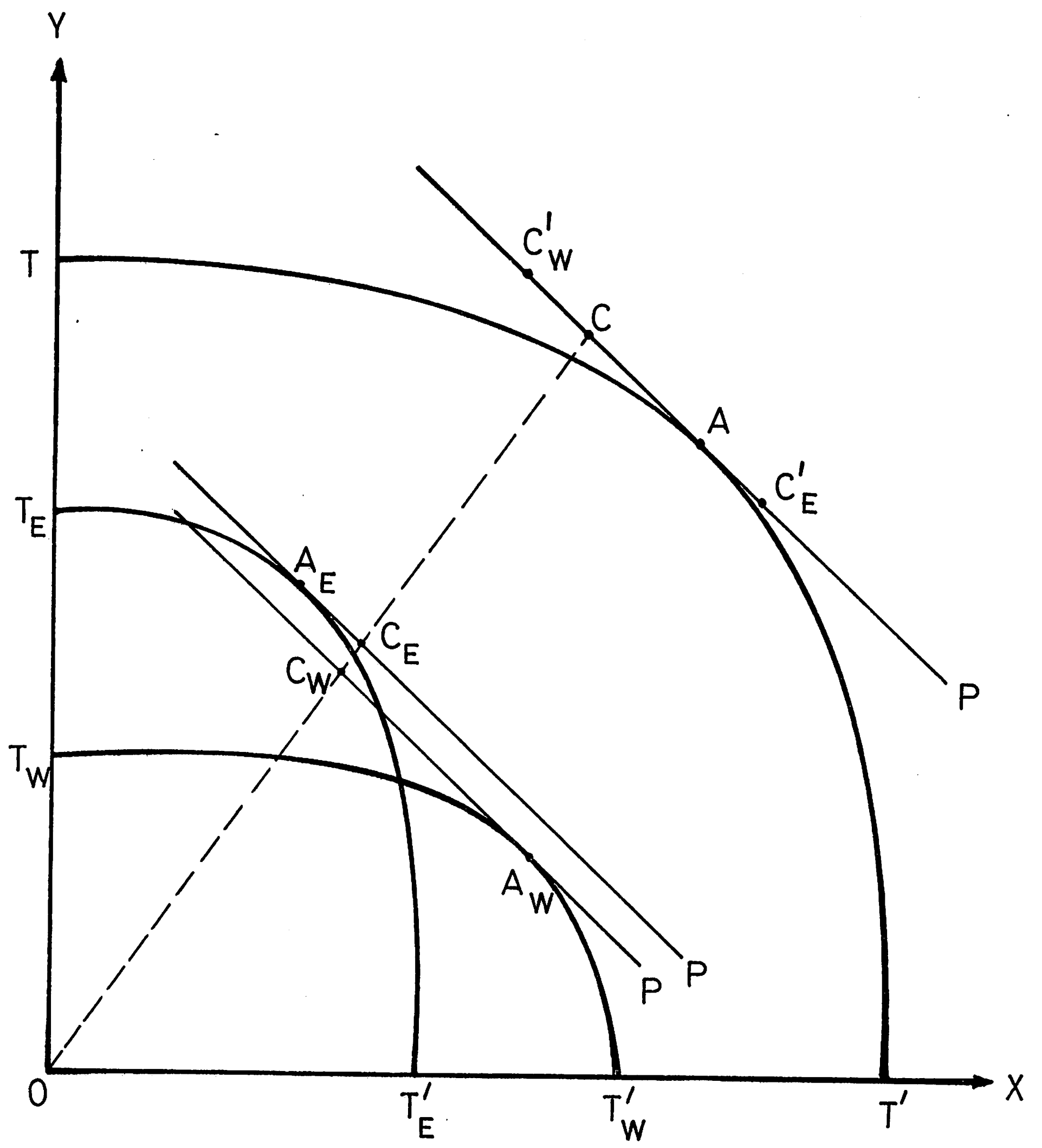

FIGURE 2 


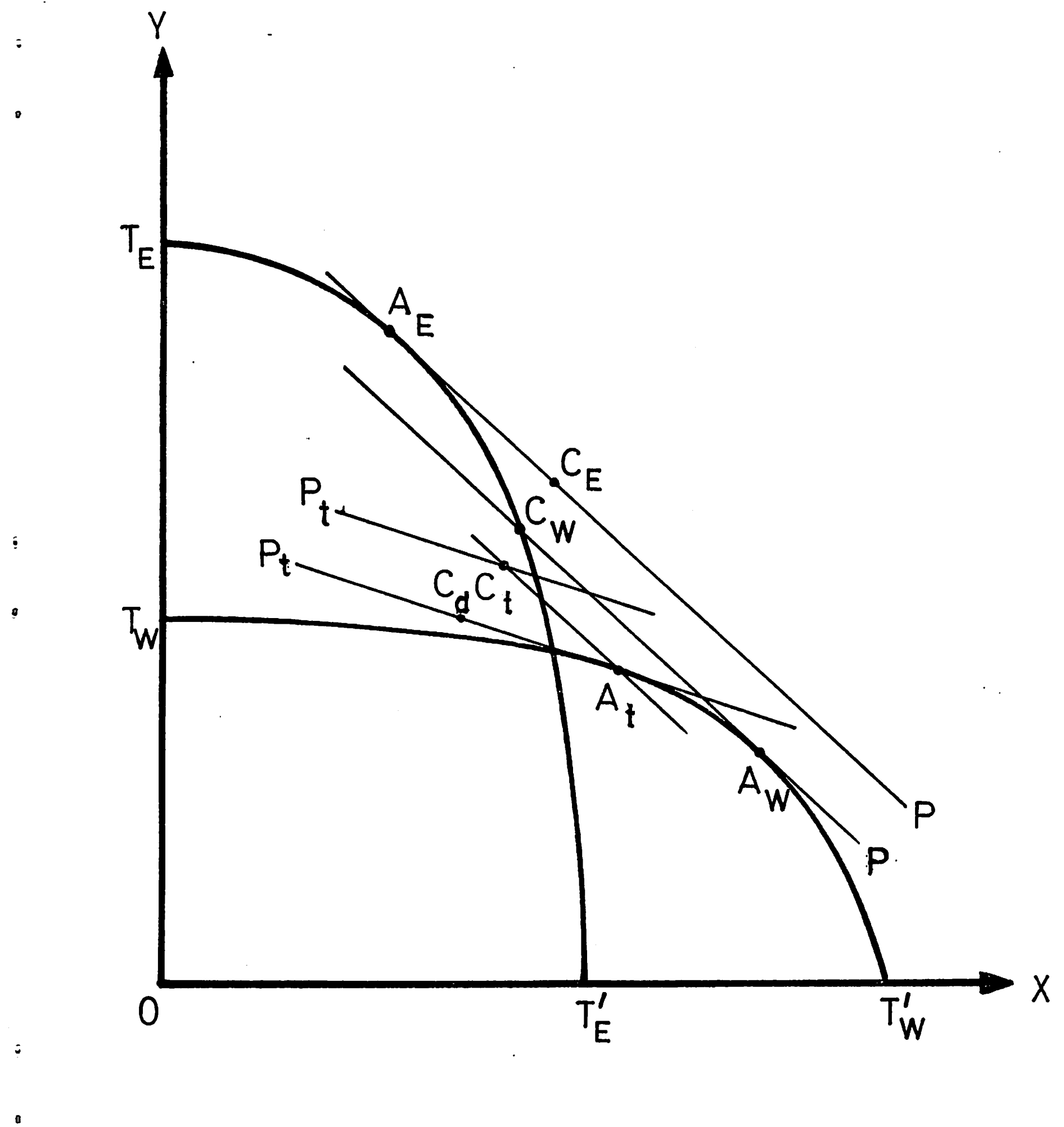

FIGURE 3 


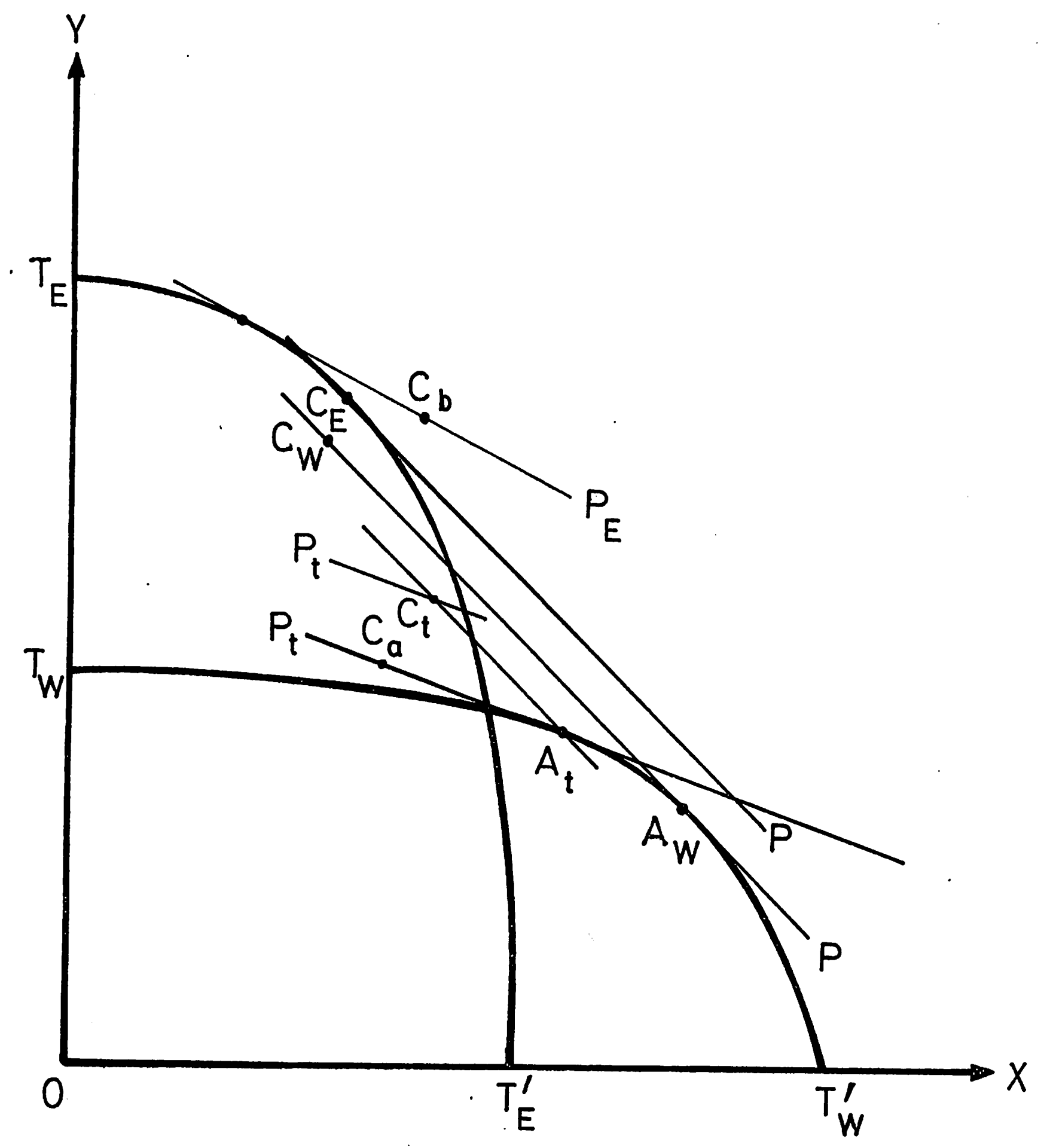

FIGURE 4 


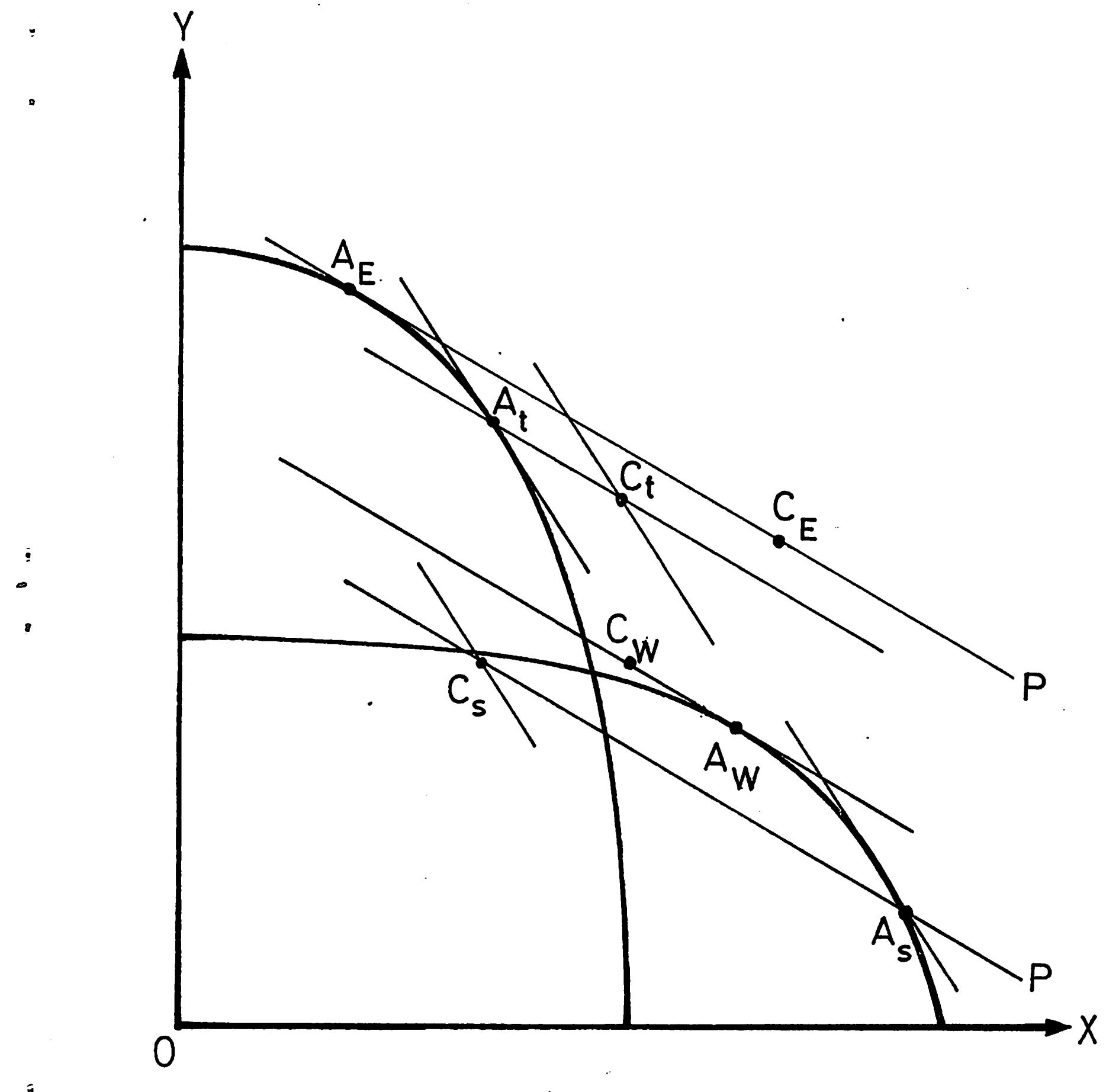

FIGURE 5 


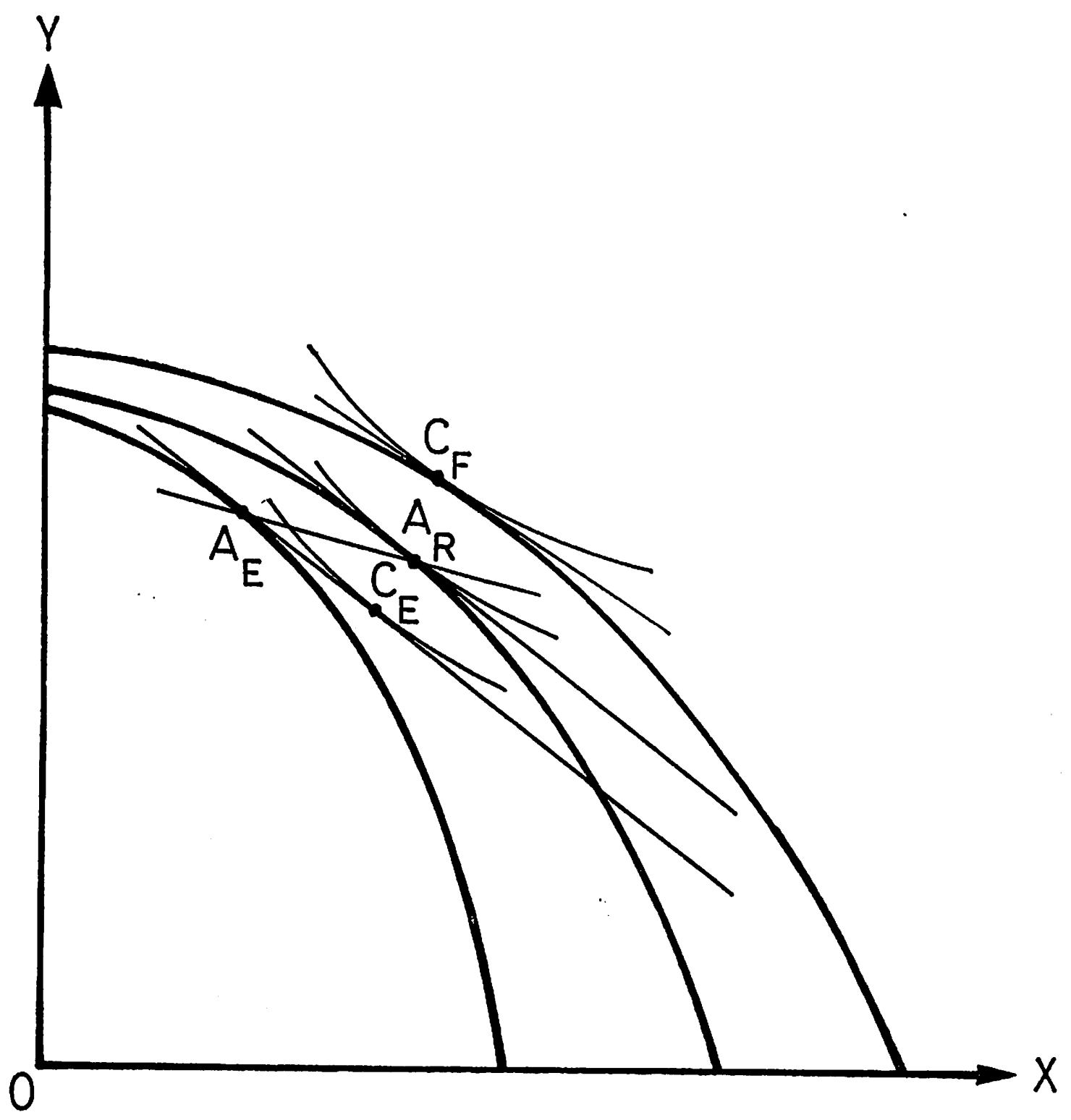

FIGURE 6 